AUTOR

\section{Antonio Maura*}

amauraba@

gmail.com

* Director del Instituto Cervantes de Río de Janeiro (Brasil). Socio correspondiente de la Academia Brasileña de Letras (ABRL, Brasil).

\section{Lorca y Brasil}

\author{
Lorca e o Brasil
}

Lorca and Brazil

\section{RESUMEN}

Federico García Lorca, acompañado por Manuel Fontanals, estuvo en Río de Janeiro en dos ocasiones, cuando estaba de camino a Buenos Aires, en 1933, y a su regreso un año más tarde. Apenas tuvo doce horas para pasear y conocer la capital carioca. En ambas ocasiones fue recibido y acompañado por Alfonso Reyes, entonces embajador de México en Brasil. De estas dos visitas sólo quedó una pequeña reseña en el diario vespertino $A$ Noite. Sin embargo, su obra no será conocida hasta después de su muerte $y$, especialmente, gracias al estreno en Río de Janeiro de Bodas de sangre, en 1944. Evaluar la repercusión de su obra y los ecos de su muerte es el propósito de estas páginas en las que se recogen las primeras opiniones en Brasil sobre su persona y su producción artística.

\section{RESUMO:}

Federico García Lorca, acompanhado por Manuel Fontanals, esteve duas vezes no Rio de Janeiro, a caminho de Buenos Aires, em 1933, e no seu retorno um ano depois. Ele mal tinha doze horas para andar e conhecer a capital carioca. Em ambas as ocasiões ele foi recebido e acompanhado por Alfonso Reyes, então embaixador do México no Brasil. Dessas duas visitas ficou apenas uma pequena crítica no jornal noturno A Noite. No entanto, o seu trabalho não foi conhecido até depois da sua morte e, especialmente, graças à estreia no Rio de Janeiro de Bodas de Sangue, em 1944. Avaliar o impacto do seu trabalho e os ecos da sua morte é o propósito destas páginas, que apresentam as primeiras opiniões, no Brasil, sobre sua pessoa e sua produção artística.

\section{ABSTRACT:}

Federico García Lorca, accompanied by Manuel Fontanals, was in Rio de Janeiro twice, on his way to Buenos Aires, in 1933, and on his return a year later. He barely had twelve hours to walk and get to know the capital of Rio de Janeiro. On both occasions he was received and accompanied by Alfonso Reyes, then ambassador of Mexico in Brazil. About these two visits there was only a small review in the evening paper A Noite. However, his work will not be known until after his death and, especially, thanks to the premiere in Rio de Janeiro of Blood Wedding, in 1944. Evaluating the impact of his work and the echoes of his death is the purpose of these pages in which the first opinions in Brazil about his person and his artistic production are collected. 
En dos ocasiones Federico García Lorca pisó tierra brasileña y, concretamente, las dos fueron en Río de Janeiro: el 9 de octubre de 1933, cuando el trasatlántico Conte Grande le llevaba a Buenos Aires y se detuvo por unas horas en el puerto carioca; y el 30 de marzo de 1934, cuando ya de regreso, el Conte Biancamano atracó en los muelles de Río. En ambos casos Lorca estuvo apenas unas horas en la ciudad y fue recibido y agasajado por el embajador de México en esta ciudad, Alfonso Reyes. En la primera ocasión el escritor mexicano le hizo entrega al poeta español de los primeros ejemplares de la Oda a Walt Whitman, que se acababa de publicar en una tirada limitada en México. En esta visita a Río, en compañía del escenógrafo Manuel Fontanals y del propio escritor mexicano, recorrieron por unas horas las calles cariocas y la Bahía de Guanabara antes de volver al barco que les conduciría a Santos - donde permanecería en el trasatlántico -, Montevideo y Buenos Aires.

En la segunda ocasión, ya de regreso a España, Lorca estaba también acompañado por Fontanals y fueron recibidos nuevamente por el embajador de México que, además de regalarle al poeta un estuche de cristal con mariposas tropicales, que Federico guardará con afecto expuesto en su piso madrileño, les condujo a la redacción del diario $A$ Noite, que al día siguiente publicará la imagen de un Lorca exultante acompañado por Fontanals y Reyes. Reproduzco el texto completo del artículo, que no lleva firma:

A bordo do "Conte Biancamano" que hoje tocou em nosso porto, passaram pelo Rio duas figuras muito estimadas nas letras e nas artes hespanholas: García Lorca e Manuel Fontanales.

García Lorca tem lugar destacado entre os poetas festejados da nova geração de sua pátria. As suas produções literárias, os poemas lyricos e as comédias de factura moderna, cedo Ihe deram o renome e a fama que gosa hoje, e que já transpuzeram as fronteiras da Hespanha, para repercutirem e se espalharem no estrangeiro.

Manoel Fontanales conquistou, por sua vez, nome na pintura, particularmente na scenographia, em que é um dos profissionais hespanhoes justamente considerados.

O Sr. Alfonso Reyes, embaixador do México, que foi recebel-os a bordo, teve a gentileza de acompanhal-os em visita à redacçâo d'A Noite. Lorca e Fontanales regressam de brilhante tourné à América do Sul, e associados, obtiveram nas Republicas dessa parte do nosso continenete os mais brilhantes sucessos.

O embaixador mexicano falou-nos de ambos com enthusiasmo. Acerca de García Lorca, disse-nos que é hoje, talvez, o mais festejado dos poetas moços da Hespanha. As obras de Lorca, acrescentou o distinto diplomata, alcançam sempre os maiores exitos de livraria, não só na terra pátria, mas em todos os paízes onde se fala a língua castelhana.

A crítica dos paizes que acaba de percorrer, notadamente a de Buenos Aires e a de Montevideo, não Ihes regateou aplausos e louvores.

Quanto a Fontanales, o pintor catalão, não foi menos justa a mesma crítica.

Os dois festejados artistas hespanhoes continuaram viagem a bordo do "Conte Biancamano", de regresso á Hespanha (Anónimo, 1934, p. 2).

Nolefaltabarazónal gran polígrafo Alfonso Reyes: Lorca empiezaaserfamoso internacionalmente, al menos en Argentina, Uruguay, Cuba o México, pero, a excepción de Austregésilo de Athayde a quien conoce en Buenos Aires - como informa el académico Cícero Sandroni (Sandroni, 1998, pp. 322-323) -, no entrará en contacto con ningún escritor brasileño. Es importante señalar, que entre 1933 y 1934, descollaban, entre otros, como símbolos de una edad dorada, poetas como Carlos Drummond de Andrade, Manuel Bandeira o Mário de Andrade, novelistas como José Lins do Rêgo o Jorge Amado, pintores como Cándido Portinari o ensayistas como Gilberto Freyre, que ya había publicado Casa Grande \& Senzala. Sin embargo, ninguno de los que vivían, o se encontraban en Río, fue a recibir a Lorca ni se entrevistó con él. Simplemente no le conocían.
PALABRAS CLAVE

García Lorca;

Brasil; Bodas de sangre; Yerma;

La casa de

Bernarda Alba.

PALAVRAS-CHAVE

García Lorca;

Brasil; Bodas de

Sangue; Yerma;

A casa de

Bernarda Alba.

KEYWORDS

García Lorca;

Brazil; Blood

wedding; Yerma;

The house of

Bernarda Alba.

Recibido:

26/04/2018

Aceptado:

$29 / 04 / 2019$ 
Fue su muerte ominosa en agosto de 1936, frente al revuelo en Europa, Argentina y Uruguay, la que provocó que los escritores brasileños empezaran a escribir sobre él. De hecho, en 1937, casi un año después de su muerte, en el Boletim de Ariel, Carlos Drummond de Andrade explica que sólo ha conocido a Lorca gracias a su muerte: "García Lorca, desconhecido do nosso público, só chegou até nós por essa informação rápida do assassinato do poeta pelos fascistas de Granada". En esta primera contribución, en este llamamiento a la intelectualidad y al público brasileño del valor del poeta asesinado, Drummond añade que Garcia Lorca "soube distinguir entre as contradições de sua pátria e achar, através dellas, o seu justo caminho. Ficou com o povo, apropriando-se assim do opulento cabedal lyrico que o povo costuma oferecer aos que realmente o penetram e assimilam". El gran poeta de A rosa do povo ya vislumbra en estas palabras el famoso poemario que publicará en 1945. Lorca es, sin duda, un poeta popular, pero también culto. Alguien que ha sabido aunar la erudición de la gran poesía española de Gongora o de Lope con las voces del 'cante jondo' y las historias que ha oído relatar a las criadas de su casa o a las gentes de la Vega de Granada. Termina su panegírico Drummond diciendo: "Fuzilaram o poeta... Mas o poeta continua... A poesia está viva, e sua luz de tão fulgurante, algumas vezes torna-se incommoda" (Drummond de Andrade, 1937, pp. 34-35).

Como recuerda Syntia Pereira Alves, ese mismo año, Mauro de Alencar esbozó el primer análisis de la obra del poeta granadino, que se publicó en la revista Rumo: "Vida, mundo e obra de FGL", que inauguraría una larga serie de estudios literarios y biográficos del autor de Granada (Pereira Alves, 2012, p. 1196). Sin embargo, es muy distinta la repercusión que recibe a su muerte el poeta en Argentina, donde se había dado a conocer en el viaje comentado anteriormente. El 10 de septiembre de 1936, apenas un mes después de su asesinato, Pablo Rojas Paz publicaría en el periódico Crítica, de Buenos Aires, un artículo en el que afirmaba: "Porque la muerte no puede matar la palabra, porque la muerte no puede matar a un poeta, porque la muerte no puede matar a España" (Larrea, 2015, p. 254). Algunos días más tarde, un grupo de intelectuales argentinos, entre los que se encontraban el mencionado Rojas Paz y un joven Jorge Luis Borges, enviaron una carta-telegrama a la Junta de Burgos, que representaba la jerarquía militar de los sublevados, en la que denunciaban la muerte del poeta por hombres, decían, "que, directa o indirectamente, actúan a sus órdenes" y que "a la sombra de la bandera que pretende reivindicar el esplendor de las antiguas glorias españolas, ha sido brutalmente apagada una de la voces más puras y nobles de la Nueva España." Y concluye afirmando que "la noble sangre de Federico García Lorca, que solo corrió impulsada por el amor a la belleza y a la justicia, ha puesto una nueva mancha, imborrable esta vez, sobre las espaldas culpables de su muerte" (Larrea, 2015, p. 259).

Muchos fueron los periodistas y escritores argentinos que escribieron denunciando la muerte de Lorca por los miembros parafascistas del nuevo régimen español que lideraba el general Franco. Y a los articulistas sucedieron los poetas. Quizás uno de los primeros, el argentino Conrado Nalé Roxlo, publicó en octubre de 1936 este soneto:

La alta torre de Dios yace abatida, polvo celeste en pólvora quemado, río de sol y nardos apagado bajo el puente redondo de tu herida.

El alto cielo tu silencio mida, haz de flores y flechas disparado hacia la eternidad y enraizado en el hondo diamante de la vida.

En los lirios de Góngora, crespones, en las rosas de Lope, llanto y duelo, lágrimas de poetas y leones 
acompañen tu entrada al ancho cielo, sueño de muerte, para ti desvelo en la luz matinal de tus canciones (Larrea, 2015, pp. 268-269).

Lorca entraba así, en la gloria de la más alta literatura española como uno de los defensores de la libertad y del pueblo español, a quien habían asesinado los fascistas, que eran también los enemigos a muerte de la cultura. Lorca era el poeta del pueblo, según afirmaba Cayetano Córdova Iturburu, miembro de la Agrupación de Intelectuales, Artistas, Periodistas y Escritores argentinos (AIAPE) (Larrea, 2015, p. 266). Al soneto de Nalé Roxlo, que he reproducido, se sucederán en Argentina números poemas, publicados en revistas o en libros, glosando el asesinato del poeta. No se puede olvidar tampoco, porque laten aún en nuestros oídos, aquellos versos de la Oda a Federico García Lorca, también de 1936, que después formarán parte del poemario España en el corazón (1937), de Pablo Neruda:

Si pudiera llorar de miedo en una casa sola,

si pudiera sacarme los ojos y comérmelos,

lo haría por tu voz de naranjo enlutado

y por tu poesía que sale dando gritos.

Porque por ti pintan de azul los hospitales

y crecen las escuelas y los barrios marítimos,

y se pueblan de plumas los ángeles heridos... (Neruda, 1937, s. p.).

Sin embargo, en Brasil habría que esperar al año 1944, que fue también el del estreno de Bodas de sangre en Río de Janeiro. Ante los intelectuales brasileños, Lorca vuelve a convertirse en un defensor de la libertad, de las clases oprimidas y de la poesía - la voz - asesinada. Los escritores brasileños que colaboraron con el número que la revista Leitura dedicó a García Lorca ese año como, entre otros, Mário de Andrade, Rachel de Queiroz y Cecilia Meireles, también traductora de la pieza teatral lorquiana, o Dulcina de Morais, responsable del montaje de la obra, reivindicaron la figura del poeta contra dictadores como Franco o Getúlio Vargas en los tiempos del Estado Novo. En ese número de la revista Leitura, Mário de Andrade publicó el artículo "Lorca, pobres de nós!" donde expresaba este sentimiento de falta de solidaridad ante la injusticia y la falta de libertad. Lorca ha sido ignorado en Brasil, su muerte ha pasado desapercibida, ipobre de nosotros!, se lamenta el gran intelectual brasileño:

Nos falta sentimento de classe, nos falta solidariedade coletiva, nos falta confiança na idéia. Por isso não conseguimos nos assustar com crimes contra a inteligência no mundo. Por isso não percebemos que com o assassinato de Lorca sofríamos também uma espécie de morte. [...] O assassínio de Lorca inventa a supressão da Inteligência - essa inteligência que ainda pode pensar calada, que acusa ainda quando muda, e que é a única forma de liberdade nas ideologias totalitárias. O assassínio de Lorca ordena que é preciso matar o pensamento libre (Andrade, 1944, p. 7).

Manuel Bandeira, que ya conocía la obra de Lorca en su idioma original, imparte un curso de poesía, donde analiza los poemas del autor de Bodas de sangre. También escribe un poema en su honor, que publica en su libro Belo Belo, de 1948. En él se glosa el poema de Neruda y se manifiesta el amor por la libertad y por la España auténtica, no la de Franco, ni la del Cid, ni del Gran Capitán, sino la de Teresa de Jesús, de Juan de la Cruz, de Lope, Góngora y Cervantes:

A Espanha de Franco, não!

Espanha republicana,

noiva da revolução!

Espanha atual de Picasso,

de Casals, de Lorca, irmão 


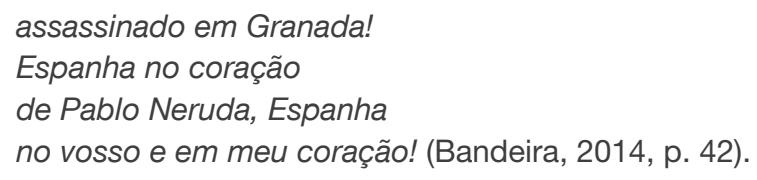

Luego llegaron nuevos poemas de Drummond, de Vinícius de Moraes, que tanto tenía en común con el poeta de Granada - poeta y músico -, de Murilo Mendes, de Hilda Hilst, de Lêdo Ivo y de tantos otros. Pero, entre las voces, los poemas, no puedo dejar de recordar las palabras que le dedicó con el título de Morte de um pássaro (Réquiem para Federico Garcia Lorca), Vinícius, autor de tantas y tantas canciones, y de versos inolvidables:

Ele estava pálido e suas mãos tremiam. Sim, ele estava com medo porque era tudo tão inesperado. Quis falar, e seus lábios frios mal puderam articular as palavras de pasmo que lhe causava a vista de todos aqueles homens preparados para matá-lo. Havia estrelas infantis a balbuciar preces matinais no céu deliquescente. Seu olhar elevou-se até elas e ele, menos que nunca, compreendeu a razão de ser de tudo aquilo. Ele era um pássaro, nascera para cantar. Aquela madrugada que raiava para presenciar sua morte, não tinha sido ela sempre a sua grande amiga? Não ficaria ela tantas vezes a escutar suas canções de silêncio? Por que o haviam arrancado a seu sono povoado de aves brancas e feito marchar em meio a outros homens de barba rude e olhar escuro?

Pensou em fugir, em correr doidamente para a aurora, em bater asas inexistentes até voar. Escaparia assim à fria sanha daqueles caçadores maus que o confundiam com o milhafre, ele cuja missão era cantar a beleza das coisas naturais e o amor dos homens; ele, um pássaro inocente, em cuja voz havia ritmos de dança. [...]

Sim, teve medo. E quem, em seu lugar, não o teria? Ele não nascera para morrer assim, para morrer antes de sua própria morte. Nascera para a vida e suas dádivas mais ardentes, num mundo de poesia e música, configurando na face da mulher, na face do amigo e na face do povo. Se tivesse tido tempo de correr pela campina, seu corpo de poeta-pássaro ter-se-ia certamente libertado das contingências físicas e alçado voo para os espaços além; pois tal era sua ânsia de viver para poder cantar, cada vez mais longe e cada vez melhor, o amor, o grande amor que era nele sentimento de permanência e sensação de eternidade.

Mas foram apenas outros pássaros, seus irmãos, que voaram assustados dentro da luz da antemanhã, quando os tiros do pelotão de morte soaram no silêncio da madrugada (Moraes, 1976, pp. 529-530).

Ciertamente, fue una madrugada cuando murió el poeta del Romancero Gitano, según ha descrito pormenorizadamente lan Gibson: una madrugada siniestra del 18 de agosto de 1936, junto a un olivar más allá del barranco de Víznar, camino de Alfacar. Vinícius recrea la escena con un verismo poético, que no se aleja demasiado de la realidad, aunque no había pájaros ni tampoco luna, pues se habría puesto en su cuarto menguante antes del asesinato. Con él fueron acribillados por las balas dos banderilleros y un maestro de escuela.

¿Lorca era un hombre político? Sin duda. Era imposible no serlo en la España de los años treinta del pasado siglo. Pero no pertenecía a ningún partido, aunque mantuviese pública y claramente su compromiso con la izquierda, leyendo poemas en una concentración masiva congregada en la Casa del Pueblo de Madrid y haciéndose socio de la recién constituida Asociación de Amigos de América del Sur (dedicada a combatir las dictaduras de Miguel Gómez en Cuba y de Getúlio Vargas en Brasil), así como del Comité de Amigos de Portugal, fundado con el objetivo de informar al público español acerca del régimen fascista de Oliveira Salazar, como indica lan Gibson. Aun así era muy crítico con la poesía de carácter confesional. Según comentó a los periodistas Ricardo F. Cabal y Francisco Herrero:

El artista debe ser única y exclusivamente eso, artista. Con dar todo lo que tenga dentro de sí, como poeta, como pintor... ya hace bastante. Lo contrario es prostituir el arte. Ahí tienen ustedes el caso de Alberti, uno de nuestros mejores poetas jóvenes que, ahora, luego de su viaje a Rusia, se ha vuelto 
comunista y ya no hace poesía, aunque él lo crea, sino mala literatura de periódico. ¡Qué es eso de artistas, de arte, de teatro proletario!... El artista, y particularmente el poeta, es siempre anarquista, sin que sepa escuchar otras voces que las que afluyen dentro de sí mismo, tres fuertes voces: la VOZ de la muerte, con todos sus presagios; la VOZ del amor y la VOZ del arte... (Cabal, 2017, p. 56).

El hecho de no militar en un partido político no impidió, como venimos diciendo, que no estuviera comprometido con la causa de la libertad y con el espíritu profundo del pueblo español y, específicamente, del andaluz. Toda su obra es la búsqueda de las raíces milenarias de una tierra y de un pueblo que, en su opinión, se remontaba al Al-Andalus, e incluso antes, a la Tartessos de Argantonio, el "hombre de plata", que para los griegos fue la primera civilización de Occidente. Ese espíritu legendario y telúrico se traslada a sus poemas y, especialmente, a las tres piezas teatrales que, de manera específica, tratan de la tierra andaluza. Me refiero a la mal denominada "trilogía" dramática de Bodas de Sangre, Yerma y La Casa de Bernarda Alba. Y digo mal llamada "trilogía" porque Lorca, que sí preveía una trilogía compuesta por la tragedia Bodas de Sangre y el poema trágico Yerma, no tenía en mente concluirla con La Casa de Bernarda Alba. En una entrevista, publicada a finales de 1934, afirma que quiere completar dicha trilogía con una pieza llamada El drama de las hijas de Lot, que, poco después, denominaría La destrucción de Sodoma. Estos dos últimos títulos se refieren a la misma obra, que posiblemente en su desarrollo creativo se haya convertido en La casa de Bernarda Alba. En ella se trata dramáticamente de las dificultades y la represión sexual de unas jóvenes, ya sean las hijas de Lot o las de Bernarda. Algunos críticos, como Allen Josephs y Juan Caballero, consideran que, aunque las tres obras glosen hechos ocurridos en el campo andaluz, no suponen una continuidad, debido a que la Casa de Bernarda parece inaugurar un nuevo modelo de teatro en el que se sintetizan todos los hallazgos técnicos y literarios que el poeta había experimentado hasta ese momento. Esta es la razón por la que prefieran agrupar a las tres obras bajo el epígrafe de "tríptico". Por otra parte, no parece lógico que las dos primeras piezas de la trilogía, o tríptico, traten sobre hechos ocurridos en Andalucía y la última acabe por ser una tragedia bíblica. Más parece que Bernarda sea la continuación de ese espíritu telúrico, que representan Bodas de sangre y Yerma, y que suponen, en palabras del propio Lorca, su conciencia y su amor a la tierra.

Bodas de Sangre, obra de dimensiones cósmicas, como la calificaría el crítico argentino Marcial de Laiglesia (Larrea, 2015, p. 137), tuvo su origen en un crimen sucedido realmente y recogido en los periódicos: cerca del pueblo de Níjar, en Almería, se había producido un misterioso asesinato en vísperas de una boda. El muerto, Curro Montes, era un antiguo amante de la novia que, al haberla secuestrado el día anterior a la boda, falleció a manos del hermano del novio. Estos hechos, recogidos en la prensa madrileña en 1928, concretamente en $A B C$ y en el Heraldo de Madrid, son el inicio de esta tragedia, donde se aúnan el misterio, el destino y la sangre. En la obra existen dos elementos simbólicos: el cuchillo y el caballo. El primero representa el sacrificio y ha sido secularmente utilizado en los ritos sagrados. El segundo alude a la fuerza bruta, al instinto, poderoso e imposible de retener. Los dos elementos son cruciales para entender la tragedia que se avecina. El segundo cuadro se inicia con la impresionante "Nana del caballo que no quiso el agua", una de las obras maestras del arte popular recogida por García Lorca:

Nana, niño, nana

del caballo grande

que no quiso el agua.

El agua era negra

dentro de las ramas.

[...]

Duermete, rosal, que el caballo se pone a llorar,

las patas heridas,

las crines heladas,

dentro de los ojos

un puñal de plata.

Bajaban al río, 
¡Ay cómo bajaban!

la sangre corría

más fuerte que el agua (García Lorca, 1972, p. 1184).

Como en las tragedias griegas, el desenlace se viene anunciando desde el comienzo. No se puede evitar, nadie puede evitarlo, pues parece estar escrito en las estrellas. La madre duerme al niño con la nana más trágica que podría cantarse, porque esa es la realidad, el sino de esta tierra y de estos personajes. La fuerza telúrica es imparable y ello simboliza el caballo, pura pasión indomable.

Por otra parte, el espacio no deja de ser especialmente arcaico: la novia vive en una cueva, como algunas de las que todavía existen en Andalucía, dando a la escena un aire arcaico y primitivo, que nuevamente enlaza con un pasado remoto y legendario.

En el tercer acto, dejando atrás a los protagonistas de la obra, entramos en un ámbito extraño. Se trata de un bosque de noche, con troncos húmedos. Este paisaje contrasta claramente con las tierras áridas de Almería y con las cuevas labradas por el viento en las faldas de sus montañas. Parece que nos encontramos en el interior de un lugar casi sagrado, como aquel bosque misterioso en el que se inicia Macbeth, más que en un paisaje andaluz de cuevas y desiertos. Lorca se sirve de los escenarios como elementos emblemáticos también y sus personajes poco pueden hacer contra estos paisajes, objetos y animales cargados de destino y de mensaje. Al poco sale la Luna, que se personifica y tiene voz, entonando un canto poético donde nuevamente se ensalza la sangre y el cuchillo. La Luna, como aquel caballo de la nana, está también helada:

La luna deja un cuchillo

abandonado en el aire,

que siendo acecho de plomo

quiere ser dolor de sangre.

¡Dejadme entrar! ¡Vengo helada

por paredes y cristales! (García Lorca, 1976, p. 1249).

Poco después, aparece la Mendiga que personifica a la muerte. La huida de los amantes está, pues, condenada al fracaso y la tragedia es inevitable. Luna y Mendiga son encarnaciones plásticas de una realidad sobrenatural. Lorca nos hace sentir esta "verdad" de forma sobrecogedora, con una plasticidad que deja de ser dramática para ser trágica en el más puro sentido griego, es decir, ceremonial. Como recuerda Ángel Álvarez de Miranda, se trata de "un tipo de religiosidad basada en sacralidades naturalistas fundadas muy especialmente sobre la sacralidad de la vida orgánica” (Álvarez De Miranda, 1965, p. 11).

Esta obra fue estrenada primero en Madrid, el 8 de marzo de 1933, con un éxito arrollador. Al estreno asistieron, entre otros, el premio Nobel Jacinto Benavente, Miguel de Unamuno, Fernando de los Ríos y las jóvenes promesas de la nueva pléyade de poetas: Vicente Aleixandre, Luis Cernuda, Jorge Guillén, Pedro Salinas y Manuel Altolaguirre. Lorca se situaba así a la cabecera de una generación que aunaba lo dramático a lo poético en una simbiosis sólo comparable a los autores del barroco y del renacimiento y, más distante aún en el tiempo, a las fuentes rituales y sagradas de la tragedia griega. El poeta de Granada llamaba así a las puertas de la antigua civilización de Argantonio y Tartessos.

Bodas de sangre fue también clamorosamente acogida en Buenos Aires, interpretada por Lola Membrives, una de las actrices argentinas más valoradas del momento. Como antes hemos señalado, algunos críticos descubrieron en ella una "dimensión cósmica", que será uno de los pilares de la futura literatura latinoamericana, de la segunda mitad del siglo XX. Obras como Pedro Páramo, Cien años de soledad, y también podríamos mencionar Grande sertão: veredas, beben de esta fuente donde lo mítico se aúna a lo cotidiano de una tierra que desdibuja sus fronteras y limita con lo sagrado o con la muerte, es decir, con los 
paisajes simbólicos del más allá humano.

En Brasil, como ya se ha dicho, el estreno de Bodas de sangre se produjo en Río de Janeiro en 1944 a cargo de la compañía Dulcina e Odilon, bajo la dirección y la interpretación de la propia Dulcina de Morais. El estreno, también exitoso, abrió los ojos de la intelectualidad brasileña hacia la obra de uno de los poetas y dramaturgos más significativos de la península ibérica, además de ser una de las víctimas de la libertad y de los derechos del pueblo siempre tan acorralados y humillados por los regímenes dictatoriales, que asolaban Europa y también, en gran medida, América latina. La obra fue traducida al portugués de Brasil por la mano maestra de Cecilia Meireles, quien en un artículo publicado ese mismo año en la revista Leitura, llama la atención sobre la importancia del autor y de su obra, más allá de las reivindicaciones y usos partidistas, intentando "não amesquinhar a memoria do poeta, e suas virtudes literárias, fazendo de seu fuzilamento razão de ser das homenagens que se lhe dirigem como a uma espécie de mera vítima política." Para Cecília Meireles, Lorca no es sólo una víctima de la represión fascista en España, sino, sobre todo, un gran poeta como se demuestra en la obra que acaba de traducir, donde

todas as figuras nos transmitem o pressentimento de sua queda fatal, tal qual no velho tema de "El enamorado y la muerte". Em todas pesa essa angústia de um estado fatal, que elas mesmas reconhecem a cada instante como destino, sina, fado - e que Ihes imprime a grandeza mitológica do drama grego (Meireles, 1944, p. 5).

Cecilia Meireles, que ha traducido Bodas de Sangre con toda su hondura poética, descubre también esa reminiscencia telúrica, griega, del poeta. Lorca, evidentemente, era mucho más que una víctima, era un autor indiscutible para la tradición cultural española e iberoamericana.

Yerma, también traducida por Cecilia Meireles, se basaba también en hechos reales. Al norte de la Vega de Granada se levanta la fortaleza de Moclín, construida por los árabes y tomada por los Reyes Católicos en 1486. Allí, Fernando e Isabel pasaron largas temporadas hasta la capitulación de la ciudad de Granada. Como muestra de su afecto al lugar regalaron a la iglesia que se levantó en ese emplazamiento el estandarte de Cristo, que habían enarbolado en toda su campaña militar contra los musulmanes del reino granadino. A lo largo del siglo XVI el lienzo adquirió poderes milagrosos y fue conocido como el Santísimo Cristo del Paño. También se fijó un día para su culto: el 5 de octubre. Con el tiempo esta festividad se volvió muy popular convirtiéndose en una peregrinación famosa en toda Andalucía. No se sabe cómo el paño sagrado llegó a tener poderes mágicos para favorecer la fertilidad femenina y lo cierto es que, cada 5 de octubre, la peregrinación de Moclín se convirtió en una larga hilera de hombres y mujeres que atravesaban la Vega para conseguir descendencia. Francisco García Lorca, hermano del poeta, recordaría que una tosca litografía del Cristo del Paño se encontraba en la pared del cuarto que compartían en su infancia. A comienzos del siglo $X X$, esta famosa romería llegó a tener cierto carácter orgiástico, de modo que muchos de los embarazos que se produjeron habría que atribuirlos más a la intervención humana que a la divina. Centenares de hombres participaban en la bacanal, mientras que las gentes gritaban a los maridos de las mujeres estériles: “¡Cornudos, cornudos!”, aludiendo a las frenéticas cópulas de éstas, que se entregarían a otros hombres para poder quedarse preñadas. Según apunta Marcelle Auclair, Lorca habría comentado al contemplar la imagen del Cristo del Paño: "En regardant bien, on peut apercevoir, sous la mince couche du repeint, les pieds fourchus et velus d'un faune..." (Auclair, 1968, p. 323). Si es cierta esta aseveración, podemos colegir nuevamente que, en Yerma, la tragedia que habría de escribir está ya larvada la tradición pagana, previa a la cristianización de la Vega de Granada y de las tierras andaluzas. Lorca volvía nuevamente a esas raíces telúricas, a la sangre y a la pasión milenaria de la tierra. De hecho en el último acto de la obra, mientras se desarrolla el canto de las mujeres estériles, tiene lugar la danza del Macho y de la Hembra, donde aquel agita desenfrenadamente un cuerno de toro como signo fálico y acosa a una Hembra fascinada, mientras el coro entona:

Si tú vienes a la romería 


\author{
a pedir que tu vientre se abra, \\ $[\ldots]$ \\ vete sola detrás de los muros \\ donde están las higueras cerradas \\ y soporta mi cuerpo de tierra \\ hasta el blanco gemido del alba (García Lorca, 1972, p. 1341).
}

Se trata, sin duda, como comenta Álvarez Miranda, de un ritual que entronca con una religiosidad arcaica, no cristiana, donde la luna y la noche, la fecundidad y el símbolo fálico, que representa el cuerno de toro, son los elementos ceremoniales.

Si Bodas de sangre era un rito que celebraba el sacrificio, Yerma es otro rito trágico que celebra la fecundidad. Tal vez, por esta razón, Lorca denominaba a estas obras tragedias y no dramas, como sería el caso de La Casa de Bernarda Alba. Esta última obra también tuvo su referente en la realidad, pues se basaba en la figura de Frasquita Alba, una vecina de los García Lorca en Asquerosa, y de forma testimonial, porque, a pesar de que fuese una mujer autoritaria, nunca llegó a los excesos de Bernarda. En todo caso, la última obra del poeta del Romancero Gitano, que no se estrenaría estando vivo, puede considerarse como la culminación de un largo proceso, que engloba las dos obras mencionadas y las tentativas de carácter más o menos surrealista de El Público y Así que pasen cinco años. Y es, en este sentido, la "expresión más radical del conflicto lorquiano entre el individuo y la sociedad”, según afirma Juan Caballero (García Lorca, 1976, p. 73). La Casa de Bernarda prescinde de situaciones mágicas explícitas, como del diálogo de la Mendiga y la Luna en Bodas de Sangre o la danza del Macho y la Hembra en Yerma, pero no de determinados símbolos que quedan larvados en la pieza: el caballo o la figura un tanto emblemática de Pepe el Romano, que no aparece nunca en escena, pero es el motor que desencadenará la tragedia, pues no se le puede dar otro nombre al triste desenlace de la obra con el suicidio de Adela, la más pequeña de las hijas de Bernarda. En el acto tercero es ésta la que frente a una noche oscurísima, sin luna, escucha o imagina al caballo en el corral: "El caballo garañón estaba en el centro del corral ¡blanco! Doble de grande, llenando todo lo oscuro”. Y luego comenta anunciando, de algún modo, el final de la pieza: "Tiene el cielo unas estrellas como puños". Adela tiene los oídos y los ojos abiertos no sólo al deseo, sino a las oscuras fuerzas que agitan al ser humano. Es el personaje que de un modo más claro se enfrenta a la tiranía de Bernarda y a los rumores y maledicencias de las gentes del pueblo. Es ella la que hace de su vida una pasión, que se entrega a ella hasta la muerte con un sino inevitablemente trágico. Por eso no necesita de rituales ajenos a los que laten en su propia sangre. En La Casa de Bernarda Alba asistimos una vez más al sacrificio de un ser humano que, por alcanzar la libertad y el derecho a vivir su propia vida, es capaz, paradójicamente, de perderla.

Por otra parte, la escena de Bernarda Alba es de una desnudez total, una sala vacía con apenas unas sillas, donde sólo hay dos colores: el blanco y el negro. En este sentido, puede compararse al Guernica, de Picasso, donde la ciudad bombardeada por los Nazis parece una habitación cerrada, igual que La casa de Bernarda, en blanco y negro. ¿Tiene algo que ver la obra de Lorca, que de alguna manera anticipa el horror de una guerra con la pintura de Picasso, que denuncia el primer bombardeo sobre una población civil? Esta obra fue traducida al portugués de Brasil, en 1968, por Clarice Lispector en colaboración con Tati de Moraes. La traducción no se ha publicado, pero me consta que ha sido representada en algunas ocasiones. He cotejado esta versión y puedo testimoniar que es correcta y que se ajusta bastante bien a los giros puramente andaluces que utiliza el poeta granadino. Y tampoco puedo dejar de notar que algunos de los símbolos de los que se sirve Lorca y que son inherentes a la trama dramática, forman parte también de la obra clariceana como el ya mencionado "caballo" o el agua, que en La Casa de Bernarda es tan importante. Estos símbolos recuerdan los potros clariceanos de $A$ cidade sitiada, el agua que inunda como un ser vivo la narración Água viva. La presencia del hombre inalcanzable, Martim, en la novela $A$ maçã no escuro, se podría comparar a Pepe el Romano en todo su valor de Macho simbólico, arquetípico. También 
en esta novela clariceana, el personaje de Ermelinda recuerda, en sus fantasías, al de Adela de La Casa de Bernarda. El número de resonancias es interminable y no deja de ser sintomático que sea esta la única obra que Clarice tradujo de Lorca, aunque apenas la menciona en sus escritos y parece que no le haya dado demasiada importancia. Sin embargo, nosotros podemos dársela, porque tanto Clarice como Federico fueron dos artistas de la palabra implicados con las simas más profundas del ser humano, con la tierra y la savia que retumba en nuestras venas, con lo remoto y lo sagrado, con los rituales ancestrales que repetimos ignorando su significado, con el misterio... "Sólo el misterio nos hace vivir, sólo el misterio", anotaría Lorca al pie de uno de sus dibujos. ¿No podría ser ésta una frase escrita por Clarice en uno de los trozos de papel en los que anotaba sus ideas súbitas? Quede esta pregunta en el aire como el grito desgarrador que se escucha al final de Bodas de Sangre o el golpe mortal con el que se cierra La Casa de Bernarda Alba. 


\section{REFERENCIAS BIBLIOGRÁFICAS}

Álvarez de Miranda, A. (1963). La metáfora y el mito. Madrid: Taurus.

Andrade, M. (1944). "Lorca, pobre de nós!" En Leitura. Río de Janeiro.

Anónimo. (1934). "García Lorca passou pelo Rio". En $A$ Noite. Río de Janeiro.

Auclair, M. (1968). Enfances et mort de Garcia Lorca. París: Seuil.

Bandeira, M. (2014). Belo belo. São Paulo: Global Editora.

Cabal, R. F. \& Pérez Herrero. (2017). "Charla con Federico García Lorca”. En V. Fernández. Federico García Lorca. La canción de los chopos. Antequera: Confluencias.

Drummond de Andrade, C. (1937). "Morte de Federico García Lorca”. En Boletim de Ariel, pp. 34-35.

García Lorca, F. (1963). Yerma (C. Meireles, Trad.). Río de Janeiro: José de Aguilar.

García Lorca, F. (1972). Obras completas. Madrid: Aguilar.

García Lorca, F. (1975). Bodas de sangue (C. Meireles, Trad.). Río de Janeiro: José de Aguilar.

García Lorca, F. (1976). La casa de Bernarda Alba (A Josephs \& J. Caballero, Ed.). Madrid: Cátedra.

García Lorca, F. (s. f.). A casa de Bernarda Alba (C. Lispector \& T. Moraes, Trad.). Río de janeiro: Archivo de la Fundación Casa de Rui Barbosa.

Gibson, I. (1998). Vida, pasión y muerte de Federico García Lorca. Barcelona: Plaza-Janés.

Larrea, P. (2015). Federico García Lorca en Buenos Aires. Sevilla: Renacimiento.

Meireles, C. (1944). "Federico García Lorca". En Leitura. Río de Janeiro.

Moraes, V. (1976). Poesia e prosa. Río de Janeiro: Editora Nova Aguilar.

Neruda, P. (1937). Oda a Federico García Lorca. Recuperado de [https://www.neruda.uchile.cl/obra/ obraresidencia2h.html]. consultado [13-05-2019].

Nuñez Arca, P. (Coord.). (1944). Presença de García Lorca. São Paulo: Letras Editora Continental.
Pereira Alves, S. (2012). "Las letras en Brasil y García Lorca". En XV Encuentro de Latinoamericanistas Españoles. Congreso Internacional América Latina: La autonomía de una región. Recuperado de [https://halshs. archives-ouvertes.fr/halshs-00876607]. Consultado [1305-2019].

Sandroni, C. \& Sandroni, L. C. (1998). Austregésilo de Athayde. O século de um liberal. Río de Janeiro: Ed. Agir. 